\title{
O reuni e a inclusão social: novos desafios para a gestão universitária
}

O artigo trata dos desafios que as políticas públicas de inclusão social trazem para a gestão universitária. Tem por objetivo analisar o que dizem gestores da UFMG sobre a implantação do REUNI e inclusão social nesta Universidade. Utilizou-se como procedimentos metodológicos a pesquisa qualitativa, descritiva, que consistiu em um estudo de caso, com participação de gestores ocupantes de cargos vinculados diretamente à Reitoria e coordenadores de cursos, englobando oito grandes áreas do conhecimento. Como método de coleta de dados, utilizou-se de pesquisa documental e entrevista semiestruturada com 23 gestores. 0 tratamento dos dados foi realizado com auxílio do software IRAMUTEQ, sendo realizada análise de conteúdo. Os resultados evidenciaram que o Programa REUNI foi uma política de Governo necessária, porém insuficiente para promover a inclusão social e que a expansão de vagas por si só, não garante a inclusão social, sendo necessárias a adoção de outras políticas focalizadas que visem a garantir igualdade de condições na permanência e de participação em atividades de pesquisa e extensão, evitando-se a inclusão excludente das minorias.

Palavras-chave: Políticas públicas; Reuni; Inclusão social.

\section{The meeting and social inclusion: new challenges for university management}

The article deals with the challenges that public policies of social inclusion bring to university management. It aims to analyze what UFMG managers say about the implementation of REUNI and social inclusion in this University. Methodological procedures were used as qualitative and descriptive research, which consisted of a case study, with the participation of managers occupying positions directly linked to the Rectory and coordinators of courses, encompassing eight major areas of knowledge. As a method of data collection, we used documentary research and semi-structured interview with 23 managers. The data treatment was carried out using IRAMUTEQ software, and content analysis was performed. The results showed that the REUNI Program was a necessary Government policy, but insufficient to promote social inclusion and that the expansion of vacancies by itself does not guarantee social inclusion, and other targeted policies are necessary to guarantee equality of conditions in the permanence and of participation in research and extension activities, avoiding the exclusionary exclusion of minorities.

Keywords: Public policy; Reuni; Social inclusion.

\section{Topic: Gestão Pública}

Reviewed anonymously in the process of blind peer.
Received: 10/05/2017

Approved: 10/07/2017
Gionete Evangelista da Conceição Centro Universitário UNA, Brasil

http://lattes.cnpq.br/1118886155452407

gionetee@yahoo.com.br

Cristiana Trindade Ituassu

Fundação Getúlio Vargas, Brasil

http://lattes.cnpq.br/0999677890116941

cristianaituassu@yahoo.com.br

\section{Luiz Paulo Ribeiro}

Universidade Federal de Minas Gerais, Brasil http://lattes.cnpq.br/4707346826137662

luizribeiro@live.com
Referencing this:

CONCEIÇÃO, G. E.; ITUASSU, T. C.; RIBEIRO, L. P.. O reuni e a inclusão social: novos desafios para a gestão universitária. Revista Brasileira de Administração Científica, v.8, n.2, p.131-146, 2017. DOI: http://doi.org/10.6008/SPC2179-684X.2017.002.0009 


\section{INTRODUÇÃO}

$\mathrm{Na}$ administração, o conhecimento é considerado um recurso valioso que pode ser transformado em inovação, tornar-se vantagem competitiva e trazer retorno financeiro às organizações (DRUCKER, 1994). Em escala, imagina-se que isso contribuiria para o desenvolvimento de um ambiente mais competitivo e mais próspero.

Uma educação superior de qualidade, capaz de desenvolver o pensamento científico, reflexivo e crítico, pode proporcionar condições competitivas semelhantes para pessoas de renda, raça ou gênero diferentes, trazendo em si a possibilidade de contribuir para o rompimento de um ciclo de desigualdades (PASTORE et al., 2000; GIRON, 2008). Quando assume esse compromisso, a educação pode ser vista como fonte de emancipação social, ao formar indivíduos capazes de perceber seu papel na construção de uma sociedade mais humana e democrática.

O governo brasileiro, desde 2005, tem implementado políticas públicas com o propósito de democratização do acesso ao ensino superior brasileiro, isto é, de dar possibilidade de igualdade de condições de acesso e permanência de jovens a um curso superior. Dentre as iniciativas estão o Programa Universidade para Todos, a Universidade Aberta do Brasil e o Programa de Apoio a Planos de Reestruturação e Expansão das Universidades Federais (REUNI). Este último, busca, dentre outras coisas, criar condições para transformação da Universidade Pública e promover a inclusão social com a ampliação de vagas e cursos nas Instituições Federais de Ensino Superior, especialmente no turno noturno, por meio da racionalização dos seus recursos físico e humano (BRASIL, 2007). Para isto, estabeleceu-se seis diretrizes, estando dentre estas, políticas de inclusão e assistência estudantil (BRASIL, 2007).

A inclusão social, entendida como uma tentativa de minimizar as diferenças sociais vivenciadas por parte da população historicamente excluída (PRESTES et al., 2012), é um tema que tem despertado a atenção dos estudiosos recentemente, e fomentado discussões (POCHMANN, 2005; VEIGA-NETO et al., 2011). Preocupações com a inclusão social e medidas para combatê-la justificam-se na medida em que buscam diminuir a segregação, a marginalização e os desequilíbrios sociais, proporcionando oportunidades de igualdade e justiça social, além de criar condições para que o indivíduo possa ter controle de sua própria vida e exercer sua cidadania (MEYER et al., 2014).

Assim, a inclusão social parece presente entre as preocupações do Estado e da sociedade civil impactando nas atividades de gestão, como tem ocorrido nas universidades públicas. Desse modo, considerando a relevância do tema inclusão social no ensino superior, realizou-se pesquisa com o objetivo de analisar o que gestores da UFMG dizem sobre a implantação do Programa REUNI e a inclusão social nesta Universidade.

\section{METODOLOGIA}

A pesquisa foi desenvolvida respeitando-se as questões éticas adequadas à legislação, assim como o respeito ao sigilo quanto a identificação dos participantes. Realizou-se uma pesquisa de abordagem de 
natureza qualitativa, descritiva em relação aos fins, utilizando como método um estudo de caso, tendo como unidade de análise a UFMG devido a sua relevância para o Estado.

O método de coleta de dados utilizado foi através de entrevistas semiestruturadas e a técnica de análise de dados empregada foi a análise de conteúdo seguindo-se as orientações de Bardin (2011), sendo a exploração e tratamento dos dados realizados com o auxílio computacional do software Interface de R pour les Analyses Multidimensionnelles de Textes et de Questionnaire (IRAMUTEQ), que segundo Camargo et al. (2013), é apenas uma ferramenta de apoio à análise de conteúdo, ficando a cargo do pesquisador a exploração dos gráficos e interpretação dos seus resultados dentro de um contexto.

A seleção dos participantes foi intencional visando atingir todas as grandes áreas do conhecimento. As entrevistas foram realizadas individualmente, no período de agosto a outubro de 2016, com 23 gestores, resultando em um total de 877,16 minutos de gravação. Os gestores foram divididos em dois grupos, sendo um denominado ALFA, formado por 7 gestores que analisaram a viabilidade de adesão da Instituição ao REUNI e de ocupantes de cargos de livre nomeação do Reitor.

O segundo grupo, denominado BETA, foi composto por 16 coordenadores de cursos das áreas de conhecimento: Agrárias; Biológicas; Engenharias; Exatas e da Terra; Humanas; Linguística, Artes e Letras; Saúde e Sociais Aplicadas. Além das variáveis, criou-se uma variável chamada de tempo de Universidade, considerando os participantes que entraram na Universidade antes e depois de 2007, ano de discussão do REUNI. Outra variável criada foi área, condensando as áreas de atuação dos entrevistados em três áreas: Exatas e da Terra, Humanas e Sociais Aplicadas, e da Saúde.

Isso foi feito porque suspeitou-se que poderia existir alguma diferença entre a visão dos sujeitos que planejaram a implementação do REUNI na Universidade, e aqueles que efetivamente o implementaram. Da mesma forma, talvez existissem diferenças de pensamento por área de conhecimento. Compreender esse aspecto só foi possível, portanto, evidenciando-se a que grupo pertencia cada participante da pesquisa.

\section{Análise dos dados}

As entrevistas foram tratadas e submetidas ao software Iramutec que dividiu o corpus textual em 1948 segmentos de textos, sendo analisados 1630, o que representa $84.14 \%$. O software identificou 6.426 palavras ou formas distintas, em 69.367 ocorrências. As palavras foram reduzidas a 4.059 raízes léxicas, contendo 3.615 formas ativas ${ }^{1}$ e 140 formas suplementares ${ }^{2}$. Submetidos à Classificação Hierárquica Descendente, a partir do levantamento quantitativo das palavras e do seu contexto, os dados foram divididos em classes pela semelhança léxica considerando a frequência da palavra maior que a média do corpus, e determina as variáveis pertencentes a cada classe pelo qui-quadrado igual ou superior a 3.

O software Iramutec instituiu 5 classes, sendo estas posteriormente denominadas de categorias, analisadas à luz do que disseram os gestores participantes e interpretadas com base na Análise de Conteúdo

\footnotetext{
${ }^{1}$ Formas ativas são palavras identificadas a partir das formas reduzidas das raízes léxicas considerando-se os adjetivos, substantivos, formas não reconhecidas e verbos.

2 Formas suplementares são palavras identificadas a partir das formas reduzidas das raízes léxicas de adjetivos complementares, substantivos complementares e verbos auxiliares.
} 
de Bardin (2011), sendo essas assim intituladas: categoria 1, REUNI; categoria 2, Universidade; categoria 3, Aluno; categoria 4, Curso; e categoria 5, Inclusão Social, como se vê na figura 1, posteriormente analisadas pelos pesquisadores.

\begin{tabular}{|c|c|}
\hline \multicolumn{2}{|c|}{$\begin{array}{c}\text { Categoria } 1 \\
\text { REUNI }\end{array}$} \\
\hline \multicolumn{2}{|c|}{ ( $27,8 \%$ do corpus) } \\
\hline \multirow{6}{*}{\multicolumn{2}{|c|}{$\begin{array}{c}\text { Variáveis associadas } \\
\text { *Área de Ciências } \\
\text { Humanas Sociais } \\
\text { Aplicadas; Linguística, } \\
\text { Letras e Artes } \\
\text { * Ano de ingresso } \\
\text { anterior a } 2007\end{array}$}} \\
\hline & \\
\hline & \\
\hline & \\
\hline & \\
\hline & \\
\hline Palavra & Fq. \\
\hline Infraestrutura & 30 \\
\hline REUNI & 91 \\
\hline Recurso & 39 \\
\hline Número & 48 \\
\hline Vaga & 75 \\
\hline Expansão & 36 \\
\hline Noturno & 43 \\
\hline Expandir & 20 \\
\hline Novo & 46 \\
\hline Momento & 21 \\
\hline Projeto & 40 \\
\hline Pergunta & 17 \\
\hline Aumentar & 47 \\
\hline Ampliar & 19 \\
\hline Relação & 22 \\
\hline Criar & 45 \\
\hline Cumprir & 10 \\
\hline Diurno & 13 \\
\hline
\end{tabular}

\begin{tabular}{|c|c|}
\hline \multicolumn{2}{|c|}{$\begin{array}{c}\text { Categoria } 4 \\
\text { CURSO }\end{array}$} \\
\hline \multicolumn{2}{|c|}{ (16,6\% do corpus) } \\
\hline \multicolumn{2}{|c|}{ Variáveis associadas } \\
\hline \multicolumn{2}{|c|}{$\begin{array}{c}* \text { *Gupo beta } \\
* \text { Ano de ingresso a } \\
\text { partir de } 2007 \\
{ }^{*} \text { Sexo feminino }\end{array}$} \\
\hline Palavra & Fq. \\
\hline Curso & 45 \\
\hline Época & 20 \\
\hline Aprovar & 17 \\
\hline Ano & 55 \\
\hline Depto. & 19 \\
\hline Discussão & 24 \\
\hline Proposta & 18 \\
\hline Arquivologia & 9 \\
\hline Andar & 9 \\
\hline Turma & \\
\hline Ideia & 20 \\
\hline Entrar & 36 \\
\hline Publicar & 6 \\
\hline acompanhar & 14 \\
\hline Conversa & 7 \\
\hline Voltar & 6 \\
\hline
\end{tabular}

\begin{tabular}{|c|c|}
\hline \multicolumn{2}{|c|}{ Categoria 5 } \\
INCLUSÃO SOCIAL \\
\hline \multicolumn{2}{|c|}{ (11,9\% do corpus) } \\
\hline \multicolumn{2}{|c|}{ Variáveis associadas } \\
\multicolumn{2}{|c|}{} \\
\hline \multicolumn{2}{|c|}{} \\
\hline Palavra alfa & Fq. \\
\hline Cota & 37 \\
\hline SISU & 24 \\
\hline Cotista & 28 \\
\hline Vestibular & 17 \\
\hline Lei de cotas & 18 \\
\hline ENEM & 15 \\
\hline Não cotista & 19 \\
\hline Desempenho & 14 \\
\hline Efeito & 13 \\
\hline Bônus & 17 \\
\hline Sistema de cotas & 9 \\
\hline PROGRAD & 12 \\
\hline Avaliação & 12 \\
\hline Escola pública & 16 \\
\hline Negro & 11 \\
\hline Renda & 12 \\
\hline Socioeconômico & 10 \\
\hline Estudante & 26 \\
\hline Mecanismo & 7 \\
\hline UFMG & 36 \\
\hline
\end{tabular}

\begin{tabular}{|c|c|}
\hline \multicolumn{2}{|c|}{$\begin{array}{c}\text { Categoria } 2 \\
\text { UNIVERSIDADE }\end{array}$} \\
\hline \multicolumn{2}{|c|}{ (19,6\% do corpus) } \\
\hline \multicolumn{2}{|c|}{$\begin{array}{l}\text { Variáveis associadas } \\
\text { *Sexo masculino } \\
\text { * Área da Saúde, } \\
\text { Biológicas e Agrárias }\end{array}$} \\
\hline Palavra & Fq. \\
\hline País & 31 \\
\hline Qualidade & 28 \\
\hline $\begin{array}{c}\text { Ensino } \\
\text { fundamental }\end{array}$ & 14 \\
\hline Papel & 19 \\
\hline Dever & 35 \\
\hline Carreira & 12 \\
\hline Formar & 37 \\
\hline Sociedade & 24 \\
\hline Melhorar & 18 \\
\hline Pesquisa & 29 \\
\hline Ensino básico & 13 \\
\hline Ensino & 19 \\
\hline Formação & 28 \\
\hline Saúde & 17 \\
\hline Importante & 27 \\
\hline Serviço & 14 \\
\hline Médico & 12 \\
\hline Ensino médio & 18 \\
\hline Brasil & 25 \\
\hline Brasileiro & 13 \\
\hline
\end{tabular}

\begin{tabular}{|c|c|}
\hline \multicolumn{2}{|c|}{$\begin{array}{c}\text { Categoria } 3 \\
\text { ALUNO }\end{array}$} \\
\hline \multicolumn{2}{|c|}{ (24,2\% do corpus) } \\
\hline \multicolumn{2}{|c|}{$\begin{array}{c}\text { Variáveis associadas } \\
\text { * Área de Ciências } \\
\text { Exatas e da Terra, } \\
\text { Engenharias }\end{array}$} \\
\hline Palavra & Fq. \\
\hline Dia & 27 \\
\hline Aluno & 143 \\
\hline Trabalhar & 46 \\
\hline Estudar & 31 \\
\hline Ficar & 51 \\
\hline Pagar & 20 \\
\hline Empresa & 20 \\
\hline Dar & 75 \\
\hline Valer & 11 \\
\hline Aula & 20 \\
\hline Mercado & 23 \\
\hline Trabalho & 25 \\
\hline Mundo & 21 \\
\hline Sair & 23 \\
\hline Entender & 25 \\
\hline Estágio & 11 \\
\hline Visão & \\
\hline Diferença & 18 \\
\hline Entregar & 9 \\
\hline
\end{tabular}

Figura 1: Dendograma de Análise de Classificação Hierárquica Descendente sobre o que dizem os gestores da UFMG sobre o REUNI e a Inclusão Social.

Os dados da pesquisa indicaram que a categoria 1, denominada REUNI, foi estruturada a partir da contextualização, das metas pactuadas e das dúvidas envolvidas ao seu redor, representando $27,8 \%$ do que foi dito pelos participantes. Nesta categoria, a variável tempo "AR", antes do REUNI, se destacou, podendo se justificar pela própria contextualização do Programa. Outra variável presente foi a área 2, a qual integram os cursos das áreas de Ciências Humanas Sociais Aplicadas; Linguística, Letras e Artes, sendo esta a que apresenta maiores problemas de falta de espaço e de obras inacabadas.

Os elementos que compõem esta classe sugerem um vínculo com metas, como se vê pela presença dos verbos 'expandir', 'criar', 'aumentar', 'cumprir', além da preocupação com questões relacionadas à infraestrutura necessária para implantação dos objetivos propostos e do acolhimento a um número maior de alunos.

Os dados indicam que as metas foram consideradas integralmente cumpridas, em especial por aqueles que fizeram parte do planejamento do REUNI. Segundo o relato destes, os gargalos ocorreram em decorrência de fatos imprevisíveis. Os gestores do grupo BETA, executores do planejamento, talvez por vivenciarem mais diretamente o dia a dia dos cursos, apontam o que poderia ser considerado falha no planejamento: o aumento de vagas antes de se investir na melhoria da infraestrutura. Outros relatos 
apontaram, como motivo para se aderir ao Programa, a oportunidade de se conseguir mais recursos e mais vagas docentes.

A categoria 4, CURSO, equivale a $16,6 \%$ das falas, se correlaciona com a classe 1 em um mesmo subcorpus e corresponde, junto a ela, a $44,4 \%$ do total dos relatos. Esta correlação se justifica porque uma das propostas estabelecidas pelo REUNI se vincula diretamente à ampliação de vagas, o que impacta diretamente os cursos criados e aqueles que expandiram ou não suas vagas. A variável mais significativa é tempo "DR", docentes com ingresso depois de 2007, e gestores pertencentes aos grupo 2, composta por ocupantes do cargo de coordenador de curso, sendo estes participantes, em sua maioria, empossados em vagas do REUNI.

Os elementos indicam continuidade de vinculação com metas, por meio de ações propostas para a concretização destas, como se pode notar pela utilização dos verbos 'aprovar', 'andar', 'criar', 'publicar', 'entrar', 'participar', 'acompanhar', 'voltar'. No entanto, trata-se de algo que se refere, especificamente, aos cursos.

Esta categoria indica certa continuidade de preocupação com metas. No entanto, esta difere das preocupações da categoria anterior por apresentar críticas ao planejamento e dificuldades encontradas na sua execução para que as metas fossem alcançadas. Os relatos apontam a fragmentação das análises dos projetos e a falta de avaliação crítica das propostas que foram analisadas sem considerar o todo, indicando que gargalos na comunicação continuam a existir. Revela ainda, a vontade dos gestores em transpor barreiras culturais e elitistas para promover a inclusão social na Universidade, e a necessidade de se provocar a reflexão crítica acerca da construção do conhecimento e das profissões não regulamentadas no país, além dos desafios em se conciliar grades curriculares que atendam a uma formação profissional de ponta e à produção de novos saberes científicos.

$\mathrm{O}$ ato de administrar inclui, dentre suas tarefas, a coordenação de atividades que, evidentemente, demanda algum nível de integração. Esta, por sua vez, prescinde da comunicação e, se há falhas nessa seara, seja por mecanismos institucionais ineficientes, seja porque o REUNI foi um Programa cujo término ocorreu em 2012, isso precisa ser combatido em busca de melhores resultados.

A categoria 2 - Universidade, equivale a 19,6\% das falas e se vincula em um mesmo subcorpus com à categoria 3, Aluno, totalizando juntas $43,8 \%$ do corpus A variável área 3, composta por gestores da Saúde, Biológicas e Agrárias é mais significativa nesta categoria, provavelmente, por ser uma área em que a demanda por atividades de pesquisa é voltada diretamente para o bem estar da sociedade. Assim, os elementos 'País', 'qualidade', 'ensino básico e fundamental', 'carreira', 'sociedade', 'pesquisa', 'saúde', 'médico', 'político' associados aos verbos 'dever', 'melhorar' e 'preocupar' podem ser associados ao papel da Universidade para o desenvolvimento econômico e social do País.

Nela se questiona a responsabilidade da Instituição na formação técnica, na formação de educadores e na formação de pesquisadores, trazendo uma reflexão sobre o seu papel no sistema educacional e sobre sua contribuição para o avanço socioeconômico brasileiro e uma postura crítica em relação às políticas de democratização de acesso ao ensino superior. Destaca-se o dever que da Universidade em formar e devolver 
para a sociedade profissionais altamente qualificados, que irão atuar no desenvolvimento econômico e social do País. Assim, tão importante quanto formar médicos é formar professores, engenheiros, farmacêuticos, filósofos que, desenvolvendo pesquisas, podem melhorar a qualidade de vida dos brasileiros.

Verifica-se ainda, a preocupação com a continuidade de realização de pesquisas, que no Brasil, se concentram na Universidades públicas. Mas o que mais ganhou destaque, nesta categoria, foi a preocupação com a qualidade dos níveis anteriores de ensino e a necessidade de políticas educacionais que os contemplem, dentre elas políticas de valorização da carreira dos professores do ensino básico, fundamental e médio, proporcionando, assim, condições intelectuais para que os alunos possam prosseguir os estudos, mantendo-se a qualidade no ensino universitário público.

Enquanto na categoria 3 - Aluno - equivalente a 24,2\% das falas e relacionada diretamente a categoria Universidade, evidencia-se a divergência de pensamento entre os participantes da pesquisa. Alguns dão ênfase à meritocracia e apontam para a responsabilidade individual dos alunos em transporem suas próprias dificuldades, como se coubesse exclusivamente a eles vencer esses obstáculos sem, necessariamente, algum suporte por parte do Estado. De acordo com esses participantes, para quem desigualdades de origem parecem não importar, os alunos deveriam valorizar mais o fato de frequentarem uma Universidade Pública e se esforçar para tirar o máximo proveito dessa oportunidade. Esse posicionamento vem daqueles que defendem uma visão capitalista e que acreditam que o retorno da Universidade para a sociedade consiste, sobretudo, em entregar bons profissionais.

Outros participantes, direcionam suas falas para uma reflexão a respeito de aspectos sociais, defendendo que a igualdade de acesso não garante a inclusão (VEIGA-NETO et al., 2007) e remetendo ao conceito da inclusão excludente (KUENZER, 2005, 2007), ao falarem, por exemplo, das necessidades e dificuldades enfrentadas pelo aluno que trabalha e da sua escolha por cursos noturnos, e na sua maioria, licenciatura (VARGAS et al., 2013). Essas pessoas mostraram-se preocupados com a formação integral do aluno como um ser que ser relaciona com outros e acreditam que superar as dificuldades advindas de uma condição socioeconômica inferior não é responsabilidade exclusiva do aluno e fornecer instrumentos para tal cabe, também, ao Estado.

Interessante destacar que a categoria 5, Inclusão social, diretamente abordada nas questões da entrevista, representa $11,9 \%$ dos relatos. Embora componha uma classe única, está associada com o subcorpus composto pelas categorias 2 e 3 , Universidade e Alunos, respectivamente. Isto se justifica pelo fato de a inclusão social em análise ser voltada para a inserção do aluno na Universidade, o que talvez possa explicar a ausência de verbos dentre as 15 palavras mais representativas nesta classe. Ou ainda que existe um discurso sobre o que é a inclusão social apesar de persistir naturalização de formas sutis de exclusão que chegam a passar despercebidas.

A variável grupo ALFA, composta por gestores que pensaram o REUNI, se destaca nesta categoria. Os participantes que integravam este grupo buscavam mecanismos para diminuir o elitismo na Universidade e aumentar a presença de alunos oriundos de escola pública e negros na UFMG. Nesta categoria, a inclusão social associada ao REUNI refere-se à ampliação de vagas e criação de cursos noturnos. Percebe-se que a 
adoção de ações afirmativas, como os programas de bônus, deram maior contribuição para a inclusão de minorias, como se pode verificar em estudos realizados por pesquisadores em diferentes instituições (ARANHA et al., 2012; PEIXOTO et al., 2012; BEZERRA et al., 2012).

Esse programa foi substituído pela política de cotas, que completou sua implementação em 2016, sendo reconhecida como um mecanismo de inclusão social capaz de auxiliar na diminuição de desigualdades históricas (WANDERLEY, 2007; PRESTES et al., 2012) que visa proporcionar oportunidades de igualdade e justiça social, além de criar possibilidade de emancipação ao proporcionar condições para que o indivíduo possa se emancipar e exercer sua cidadania tendo controle de sua própria vida (MEYER et al., 2014) e que de fato, proporcionou a inclusão social no acesso.

Outro ponto de destaque em relação à inclusão social relaciona-se às condições de permanência do aluno na Universidade que só em 2010, teve aumento do apoio para assistência estudantil promovida pelo PNAES com incremento nos recursos do governo federal para este fim. A UFMG, por meio da FUMP, já possuía experiência visando a permanência de alunos de baixa renda. No entanto verifica-se que o número de alunos assistidos pela FUMP não cresceu na mesma proporção da expansão das vagas.

Isto pode significar que os recursos destinados pelo Programa Nacional de Assistência Estudantil não acompanharam o crescimento da matrícula decorrente do aumento de vagas e da demanda pela implementação do sistema de cotas. Ao mesmo tempo, o reconhecimento da FUMP nos programas e ações de permanência pode eximir as gestões locais de propor ações mais simples, que não envolvam recursos financeiros.

Com relação ao rendimento acadêmico dos alunos cotistas e daqueles não cotistas, os participantes pertencentes ao grupo BETA, disseram que após a matrícula são todos alunos, não havendo nenhum tipo de distinção ou identificação de cotistas e não cotistas. Segundo eles, dados sobre o rendimento acadêmico eram extraídos pela Pró Reitoria de Graduação que realiza levantamento estatístico sobre o rendimento escolar de todos os alunos, por distintas modalidades, inclusive pela forma de ingresso, sendo que estes dados indicam rendimentos acadêmicos semelhantes entre cotistas e não cotistas.

Na análise dos relatos dos participantes da pesquisa recomenda-se certa cautela, uma vez detectadas incoerências no fato de todos os alunos se tornarem tão iguais, com rendimentos acadêmicos tão próximos, em falas tão diversificadas de identificação de demandas diferenciadas. Muito se falou sobre o déficit de conhecimento de conteúdo do ensino básico associado ao ensino público. Isto pode representar, para alguns, uma negação da realidade para garantir a continuidade das políticas de inclusão social pelo acesso e permanência, enquanto para outros, pode sugerir a ideia de que políticas desta natureza não sejam mais necessárias para diminuir as desigualdades sociais e então, propor o seu fim.

Constatou-se ainda, que diante da imprecisão do termo inclusão social e da necessidade de sua contextualização, conforme visto na revisão de literatura realizada (PAUGAM, 1996; BONETI, 2006; WANDERLEY, 2007; CASTEL, 2010; AKHRAS, 2006; VEIGA-NETO et al., 2011; SILVA, 2011; MAYER et al., 2014), outras formas de inclusão foram relatadas com exemplificação de ações adotadas na UFMG. As mais comentadas destacam o trabalho desenvolvido pelo Núcleo de Acessibilidade e Inclusão para promoção da 
acessibilidade da comunidade universitária com vários tipos de limitação, como mobilidade, visual, de audição e de saúde mental. Outro ponto considerado positivo, foi a identificação visual no crescimento da presença de negros e indígenas na Universidade, além da importância da utilização do nome social e do respeito às questões de gênero.

Assim, verificou-se que relação construída entre as categorias 1, REUNI, e a categoria 4, Curso, fundamenta-se na dinâmica envolvida para se cumprir a meta expansão das vagas que ocorreram com a criação de novos cursos ou a expansão em cursos já existentes. Na aproximação das categorias 2 e 3, Universidade e Aluno, respectivamente, há de se considerar que o aluno é o foco central da Universidade, a quem se destina o processo de construção do conhecimento desenvolvido em atividades de ensino, pesquisa e extensão.

O isolamento da categoria 5, Inclusão Social, indica que O REUNI com a expansão de vagas e cursos noturnos, por si só, não promove inclusão social das minorias excluídas, o que necessita de ações focalizadas para efetivação, beneficiando assim alunos que vivenciam situações históricas de desigualdades que os mantêm longe dos bancos das Universidades.

\section{DISCUSSÃO TEÓRICA}

\section{Políticas Públicas}

Diante da dificuldade de consenso entre os teóricos sobre o conceito para políticas públicas, alguns autores defendem que a política só pode ser adjetivada como política pública quando ela é emanada por um agente estatal com autoridade formalmente constituída, sendo sua personalidade jurídica pública, sendo esta uma abordagem estatista (SALISBURY, 1995; SOUZA, 2006; RUA, 2009). Outros autores defendem a abordagem multicêntrica, sendo que o que determina se uma política é ou não pública não é quem a formula, mas a origem do problema a ser combatido, não cabendo apenas ao governo promovê-la.

Instituições não governamentais podem promover políticas públicas, sendo o enfrentamento e solução de um problema público o determinante para sua adjetivação (SECCHI, 2010; BRESER-PEREIRA, 2000). O papel do Estado e dos atores sociais envolvidos na discussão e formulação da política pública tem pesos diferenciados de acordo com a abordagem adotada.

Há ainda, a distinção entre política de Governo e política de Estado. Para Bucci (2006) a política de Governo é integrada por ações que fazem parte de um programa dentro um mandado ou por um curto período determinado, enquanto a política de Estado ultrapassa um mandato político, tendo continuidade por décadas.

De acordo com Souza (2006), embora existam várias definições para políticas públicas, estas repercutem nas relações do Estado, das sociedades, no âmbito internacional, envolvendo campos de conhecimento da economia, da política e da sociedade, o que desperta o interesse de pesquisadores de diversas áreas. São campos multidisciplinares com caráter holístico, entre os quais há certa sinergia. Essa área do conhecimento pode ser sintetizada, segundo Souza (2006), como "[...] campo do conhecimento que 
busca, ao mesmo tempo, "colocar o governo em ação" e/ou analisar essa ação (variável independente) e, quando necessário, propor mudanças no rumo ou curso dessas ações (variável dependente)".

O Programa REUNI, de que trata este estudo, pode ser classificado como uma política pública em ambas as perspectivas, mas caracteriza-se como política pública estatal, na abordagem multicêntrica e apenas uma política pública, na estatista. Esta última é a adotada neste trabalho, em coerência com o conceito de política pública aqui assumido.

O REUNI desencadeou ações que produziram resultados impactando na dinâmica universitária e na sua relação com a sociedade, traduzindo objetivos de um governo que visava a inclusão social de minorias na Universidade pública por meio da ampliação do acesso e permanência no ensino superior. É considerado ainda, uma política de Governo que foi planejada e efetivada entre 2007 e 2012, mas que resultou em efeitos de difícil extinção ao modificar o número de vagas, cursos e a dinâmica organizacional das Universidades.

Na década de 1990 mudanças significativas ocorreram no cenário brasileiro, com a elaboração e a implementação de políticas públicas nas áreas econômica, da saúde, da assistência social, da educação. Desde então, a modernização do Estado segue com a abertura econômica, atendendo a preceitos neoliberais que nortearam o Plano Diretor da Reforma do Aparelho do Estado, visando alteração da administração pública burocrática para administração pública gerencial (BRESSER-PEREIRA, 2000).

Destas reformas a política educacional chama a atenção como parte do discurso de combate à pobreza e às desigualdades sociais, e pela influência no aspecto econômico que, segundo Dias Sobrinho (2010), na promessa neoliberal aparece em discursos "recheados de ideias e promessas de desenvolvimento a ser alcançado por meio de gestão eficiente do sistema educacional”. Para Dias Sobrinho (2010), a educação é processo contínuo de formação humana, sendo direito social do cidadão, um bem público que é dever do Estado prestar com qualidade e com iguais condições de acesso para todos.

Para um acesso democrático ao ensino superior, há necessidade de uma educação básica de qualidade como um direito de todos, proporcionando igualdade de acesso, como preconizam as diretrizes curriculares nacionais para a educação básica. Mas enquanto este direito não se concretiza, isto é, enquanto o princípio constitucional de 'igualdade de condições para o acesso e permanência na escola', estabelecido no inciso I do artigo 206 da Constituição da República Federativa do Brasil, não for efetivado, as políticas públicas educacionais focalizadas são necessárias para compensar anos de desigualdades, no País, e dar condições a jovens pobres e de diferentes etnias de ingressar no ensino superior (VARGAS et al., 2013).

\section{Inclusão Social}

A inclusão social pode ser descrita como uma tentativa de minimizar as diferenças sociais que parte da população historicamente excluída experimenta (PRESTES et al., 2012). Segundo Akhras (2011), quando se trata de inclusão é de se presumir que esta ofereça alternativas para diminuir e solucionar problemas de exclusão em diversos contextos, envolvendo participação e interação das pessoas no meio social em que estão inseridas. Segundo Akhras (2011), a definição de inclusão social vai depender do tipo de exclusão 
vivenciada. Esta pode ser de natureza econômica, cultural, de escolaridade, de etnia, por deficiência física ou mental.

O termo inclusão social se envolve em muitos dilemas, sendo considerado por Boneti (2006) mais um discurso que um conceito, por se tratar de "uma positivação em relação a uma problemática social, o da exclusão". Para o autor, a partir da análise e compreensão da dualidade "dentro/fora", "pertencimento/não pertencimento", origina-se a concepção de cidadania, considerando que o indivíduo a ser incluído na sociedade racional de direito e de Estado é aquele que tem seus direitos constitucionais violados, carecendo das condições necessárias para deles usufruir, e que, mesmo assim, participa da vida política, uma vez que é parte envolvida em conflitos e problematização social. Desse modo, fica claro que a inclusão está entrelaçada à noção de democracia, de cidadania, de emancipação, de direitos humanos (FALEIROS, 2006, VEIGA-NETO et al., 2011).

Ao abordar o tema inclusão, Veiga-Neto et al. (2011) problematiza o caráter natural a ele atribuído diante do seu uso indiscriminado para reforçar conceitos de democracia, cidadania e direitos humanos. Para os autores, também o demasiado uso do termo exclusão vem dificultando a compreensão das diferenças existentes entre as diversas categorias de excluídos, o que possibilita que indivíduos acometidos por questões distintas como econômicas, sociais, etária, de etnia, de gênero, sejam todos tratados numa mesma posição de vulnerabilidade. Assim, os autores optam por usar o termo grafado in/exclusão, a fim de marcar as relações provisórias e vulneráveis decorrentes de um Estado neoliberal.

Segundo Veiga-Neto et al. (2007, 2011), outro aspecto a se considerar sobre a inclusão, mais especificamente no âmbito escolar, é que dentro de um mesmo espaço pode haver a efetivação da inclusão ou a permanência da exclusão. Neste sentido, há de se preocupar para não se estimular a discriminação negativa que Castel (2008) assim define:

Discriminação negativa não consiste somente em dar mais àqueles que têm menos; ela, ao contrário, marca seu portador com um defeito quase indelével. Ser discriminado negativamente significa ser associado a um destino embasado numa característica que não se escolhe, mas que os outros no-la devolvem como uma espécie de estigma. A discriminação negativa é a instrumentalização da alteridade, constituída em favor da exclusão. (CASTEL, 2008)

Assim, a inclusão social no âmbito escolar tem que ser completa, evitando que os beneficiados sofram qualquer tipo de estigma, necessitando do comprometimento de todos os atores envolvidos para que a inclusão seja, de fato, efetivada. Muitas questões são levantadas em relação à lógica da exclusão includente e da inclusão excludente. De acordo com Kuenzer $(2005,2007)$, o termo exclusão includente relaciona-se à exclusão de postos de trabalhos diretos para a inclusão dos empregados em postos de trabalho precarizados pela terceirização, enquanto a inclusão excludente refere-se à proposta de inclusão escolar em vários níveis e modalidades de ensino desprovidos de qualidade.

De forma geral, a conceituação de inclusão e exclusão é tão complexa que o discurso da inclusão pode diminuir ou mascarar a problemática que envolve as questões sociais, desconsiderando fenômenos que integram a complexidade dos fatos, ocultando classes intermediárias (SILVA, 2011; CASTEL, 2010; PAUGAM, 
1996). Independentemente dessa complexidade, contudo, fica claro que, para tratar de inclusão social, é importante, primeiramente, entender como vem sendo compreendida a exclusão.

É consenso entre os autores que tanto uma, como outra, tem caráter multidimensional, sendo necessária a contextualização dos fatos, sem o que é impossível defini-los (WANDERLEY, 2007; CASTEL 2010; MAYER et al., 2014). Para Wanderley (2007) os excluídos não integram grupos temporários, tendo sentido de privação coletiva advinda de problemas sociais que se multiplicam, passando a atingir todas as classes sociais, estando relacionados à pobreza, à falta de oportunidades, à discriminação, ao desprovimento e à violação de direitos, às privações múltiplas da vida social, à marginalização pela incapacidade de produzir e de consumir, e a qualquer tipo de desrespeito e isolamento social.

No contexto brasileiro, como questão social e as relações de desigualdade tem elementos históricos relacionados à exclusão de indígenas, negros, população rural, operários e mulheres. É consenso entre os autores que a exclusão deve ser contextualizada no tempo e espaço no qual o fenômeno acontece, e também, de que o papel do Estado é fundamental no enfrentamento desse tipo de problema (WANDERLEY, 2007; BORBA et al., 2011; MATA-LIMA, 2011; AKHRAS, 2011; MEYER et al, 2014).

Assim, a inclusão pode ser tratada sob diferentes perspectivas, considerando-se a natureza da exclusão. As definições sobre inclusão social relacionam-se aos processos de inserção do indivíduo na vida econômica, social e política, da solidariedade, da diversidade, das minorias e da efetividade dos direitos sociais. A abordagem utilizada nesta pesquisa foi a inclusão social por meio do ensino superior, mais especificamente aquela introduzida pelas políticas públicas de expansão de vagas e democratização do acesso à educação superior nas instituições federais, pelo REUNI, considerando-se a expansão das vagas, a maior oferta de vagas no período noturno e as ações adotadas pela UFMG para oferecer condições igualitárias aos seus estudantes.

\section{O REUNI e a inclusão social na UFMG}

A proposta de adesão da UFMG ao REUNI já precedia de estudos para expansão de vagas, sintetizados em relatório apresentado ao Conselho de Ensino, Pesquisa e Extensão (CEPE), que auxiliou na elaboração da proposta de adesão ao programa com o projeto composto por onze capítulos, sendo o capítulo dedicado ao 'Compromisso social da Instituição' no qual constava como metas aumentar as vagas no turno da noite e adotar mecanismos de ação afirmativa voltados para alunos egressos de escola pública. Na UFMG, de 2007 a 2012, houve um crescimento de cerca de 45\% no número de vagas na graduação presencial que passou de 4.674 em 2007 para 6.790 em 2012 e os cursos noturnos ampliaram de 14 para 37 no mesmo período.

No que se refere à inclusão social, no caso da UFMG, algumas ações de inclusão social já vinham sendo adotadas, antes mesmo de sua adesão ao REUNI. Ilustrações disso incluem, desde 1993, a criação e ampliação de cursos noturnos, a presença da FUMP (Fundação Universitária Mendes Pimentel) fornecendo moradia estudantil destinada a alunos carentes de recursos financeiros, vindos de outras localidades, e 
restaurantes universitários que subsidiam alimentação para estes estudantes, além de bolsas de extensão voltadas para ações afirmativas.

Em relação a política de ação afirmativa visando a inclusão social, foi adotada foi a política de bônus, a partir do vestibular de 2009, que acrescia dez por cento na pontuação de candidatos oriundos de escola pública. Aqueles, nas mesmas condições, que também se autodeclaravam negros e pardos recebiam um adicional de cinco por cento. Esta política favorecia grupos minoritários, conjugadas com avaliação meritocrática. Há pesquisas que confirmam a inclusão mediante o aumento no número de ingressantes negros e hipossuficientes nas universidades públicas, confirmando o efeito positivo destas políticas inclusivas (ALON et al., 2007; ANDREWS, 1997; ARANHA et al., 2012).

Outros fatores de inclusão como as condições de permanência e o desempenho acadêmico devem ser considerados, trazendo a reflexão levantada por Veiga-Neto et al. (2007): "a igualdade de acesso não garante a inclusão e, na mesma medida, não afasta a sombra da exclusão", podendo acontecer de um mesmo espaço que inclui poder, também, excluir. Para Dias Sobrinho (2010), a ampliação de vagas e as políticas de inclusão apresentam, a curto prazo, solução para o problema da vulnerabilidade da população quanto à pobreza e baixa escolaridade, sem alterar, contudo, as relações na estrutura verticalizada e desigual da sociedade brasileira.

Cabe ressaltar que, a partir do REUNI, outras políticas de acesso e permanência foram propostas e implementadas, como o Plano Nacional de Assistência Estudantil (PNAES), o Sistema de Seleção Unificada (SISU) e o Sistema de Cotas. Ainda assim, contemplar as necessidades desse público permanece um desafio, dados todos os fatores que se colocam como uma barreira à sua plena inclusão, apontados por autores como Dias Sobrinho (2010) e Vargas et al. (2013), por exemplo. Daí a relevância de se compreenderem melhor as iniciativas que visam promover a inclusão social por meio da expansão de vagas com criação de cursos noturnos em Universidades Públicas.

\section{CONSIDERAÇÕES FINAIS}

Esta pesquisa teve como objetivo geral analisar o que dizem gestores da UFMG sobre a implantação do REUNI e sua relação com a inclusão social na Universidade. Verificou-se que a relação entre o Programa REUNI e inclusão social na UFMG ocorreu com a expansão de vagas, em especial, no período noturno, e por meio da política de bônus que beneficiava alunos oriundos de escola pública e, dentre estes, aqueles que se declarassem negros. Nesse sentido, as contribuições do programa existiram, mas foram limitadas, indicando que apenas aumentar vagas nas IFES não garante a inclusão social. Mostram-se necessárias, portanto, políticas específicas que contemplem o público de maior vulnerabilidade, e que lhes garanta iguais condições de permanência.

De qualquer modo, o REUNI impulsionou ações e políticas posteriores que visaram minimizar fatores históricos de desigualdade como a exclusão de pobres, índios, negros, população rural (POCHMANN, 2005; WANDERLEY, 2007; PRESTES et al., 2012; MEYER et al., 2014). Neste sentido, evidenciou-se que políticas educacionais focalizadas são mais eficazes para compensar as desigualdades históricas, possibilitando aos 
estudantes-trabalhadores e aos trabalhadores-estudantes melhorarem sua renda por meio do diploma em um curso superior, mesmo quando em cursos considerados de menor prestígio social (VARGAS e PAULA, 2013).

No caso específico do REUNI na UFMG, os dados indicaram prejuízos causados pela falta de infraestrutura física e de pessoal, em especial para os cursos ofertados no turno noturno, que não contam com o funcionamento adequado de bibliotecas, cantinas, laboratórios, transporte. Isto pode significar que a inclusão social com oferta de cursos noturnos pode acarretar a inclusão excludente (KUENZER, 2005, 2007), ao não oferecer, dentre outras coisas, as mesmas condições de infraestrutura, além de deixar prejudicadas atividades de pesquisa e extensão que não são adaptadas para atender este público. Mesmo diante desta possibilidade, os dados reforçam o que diz Dias Sobrinho (2013) de que as atuais políticas de democratização do ensino superior são satisfatórias, porém insuficientes para promover a inclusão social, inclusive o REUNI.

Os dados desta pesquisa apontam o que poderia indicar falhas no planejamento por parte da Universidade, ao aumentar as vagas e receber um contingente maior de alunos antes de se promoverem as melhorias na infraestrutura física e de se investirem na contratação de pessoal para suprir a demanda. Outra questão levantada foi a deficiência no processo de comunicação entre órgãos das Unidades Acadêmicas e os Órgãos da Administração Central da Reitoria.

Para os gestores da UFMG o REUNI tratou-se de uma iniciativa relevante, válida, com avaliação predominantemente positiva, sobretudo em função da ampliação do número de vagas na Instituição. Sua importância é reconhecida, a despeito de falhas no processo e de problemas com os quais a Universidade ainda precisa aprender a lidar.

Em relação a inclusão social, verificou-se que a UFMG já adotava medidas para ofertar possibilidades aos alunos trabalhadores de frequentarem um curso superior, intensificando a oferta de cursos noturnos após a implantação do REUNI, além de desenvolver ações voltadas para a assistência estudantil, sendo estas executadas por meio da FUMP.

Verificou-se a existência de certa dificuldade por parte dos gestores em se falar diretamente sobre inclusão socioeconômica e racial, sendo o assunto, muitas vezes, abordado de maneira implícita no conteúdo das falas dos participantes, o que reforça a ideia sobre a necessidade de ampliar o diálogo sobre ações inclusivas e melhorar o processo de comunicação.

No entanto, os entrevistados reconhecem que, no que diz respeito especificamente à inclusão social, o programa pode ter deixado a desejar, o que a análise evidenciou, grosso modo, de três formas: pelo tamanho da categoria Inclusão Social, que foi a menor dentre as cinco e reuniu menos de $12 \%$ dos termos usados nos relatos, denotando sua pouca importância no conjunto dos dados e, portanto, no âmbito do programa; pela ausência de, verbos dentre as palavras mais representativas nesta categoria, indicando a falta de ações concretas, de movimento e direcionamento nesse sentido; pela distância que essa categoria manteve das demais, que se relacionaram intimamente.

Considerando-se a abordagem adotada neste estudo de verificar a inclusão social por meio de políticas públicas de expansão e da democratização do acesso proporcionada pelo REUNI, verificou-se que 
as ações focalizadas como a políticas de bônus, posteriormente substituída pela política de cotas, parecem mais efetivas na promoção de inclusão social. No entanto, para promover condições igualitárias entre os estudantes beneficiados por estas políticas, apenas promover a igualdade no acesso não é suficiente, sendo necessárias outras políticas que garantam condições de permanência, incluindo a participação destes alunos nas demais atividades de pesquisa e extensão que integram o processo de formação pelo qual passa o estudante.

Pelo que foi possível perceber, o REUNI consiste numa iniciativa que, por si só, não conseguiria dirimir um problema tão multifacetado e com raízes tão profundas na história brasileira. Imaginar que a essa política caberia esse papel seria, portanto, tratar um tema demasiado complexo de forma rasa. A promoção da inclusão social não vai acontecer com soluções simplificadas em um único programa de governo. Ao contrário, ela demanda um conjunto variado de medidas e precisa ser empreendida por diferentes agentes, de formas distintas. Nesse contexto, o REUNI foi importante, mas de modo algum pode ser visto como uma política suficiente para dar conta do problema. Compreender isso e conhecer lacunas e potencialidades dessa experiência pode ser um passo na direção de uma sociedade mais inclusiva. Considerando todas essas questões, acredita-se que esta pesquisa cumpriu seu objetivo.

Os resultados trouxeram implicações gerenciais que indicam vários desafios para a gestão da Universidade. Dentre eles, promover maior diálogo e aproximação entre cursos e Unidades Acadêmicas, preparar os gestores para lidar com um novo perfil de estudante decorrente da entrada de um número maior de alunos carentes de recursos econômicos na Universidade, motivar servidores docentes e técnicoadministrativos para trabalhar no período noturno, pensar em ações para minimizar a deficiência de conhecimento de conteúdos básicos.

Outro desafio será dar continuidade às obras paralisadas, além de adequar a infraestrutura da Universidade para alunos com deficiência, recentemente contemplados na Lei 13.409/2016. Para o Estado, resta o desafio de tratar da deficiência apontada nos níveis de ensino anteriores e a urgente necessidade de políticas que beneficiem a melhoria da qualidade do ensino nestes níveis, além da necessidade de outros programas que complementem as iniciativas do REUNI, do SISU, da lei de cotas e de outras ações inclusivas.

Mas o maior desafio para os gestores reside em aumentar as condições para a efetivação da inclusão social, com otimização dos recursos diante das maiores restrições orçamentárias impostas pela crise financeira que o País vivencia. Esse aspecto foi mencionado pelos entrevistados, que deixaram transparecer sentimentos de angústia, frustração, medo, incerteza e insegurança diante dos cortes de gastos no orçamento que afetam diretamente atividades de ensino, pesquisa e extensão da Universidade. Afinal, ele pode comprometer, dentre outras coisas, propósitos inclusivos.

Vale lembrar, ainda, que os resultados aqui encontrados se limitam à UFMG, não se propondo este estudo a esgotar todas as possibilidades de interpretação das respostas, nem a afirmar que as mesmas circunstâncias se repetiram em outras instituições. A despeito dessas limitações, entende-se que os resultados alcançados podem contribuir ao indicar os novos desafios impostos pelas políticas de inclusão 
social, e que pesquisas sobre o tema devem ser realizadas sob a ótica dos Estudos Organizacionais, de modo que a gestão possa oferecer sua contribuição ao desafio que é administrar ações afirmativas.

Para pesquisas futuras, sugerem-se estudos que visem ampliar o debate sobre a efetividade da inclusão social no ensino superior com a expansão de cursos noturnos e daqueles criados pelo REUNI, além da evasão nos cursos; que analise os rumos da Universidade Pública no Brasil e sobre qual deve ser sua contribuição para o desenvolvimento econômico e social do País, e também estudos sobre a vida egressa dos alunos em especial dos cursos novos. Só a partir daí será possível definir ações afirmativas que, de fato, venham a contemplar as minorias excluídas, possibilitando sua efetiva participação no mundo produtivo, econômico e social.

\section{REFERÊNCIAS}

AKHRAS, F.. A inclusão social como um projeto científico: uma ontologia. Revista Inclusão Social, Brasília, v.4, n.2, p.25-37, 2011.

ALON, S.; TIENDA, M.. Diversity, opportunity, and the shifting meritocracy in higher education. American Sociological Review, v.72, p.487-511, 2007.

ALVINO-BORBA, A.; MATA-LIMA, H.. Exclusão e inclusão social nas sociedades modernas: um olhar sobre a situação em Portugal e na União Europeia. Serviço Social \&

Sociedade, São Paulo, n.106, p.219-240, 2011.

ANDREWS, G. R.. Ação afirmativa: um modelo para o Brasil? In: SOUZA, J.. Multiculturalismo e racismo: uma comparação Brasil-Estados Unidos. Brasília: Paralelo 15, 1997. p.137-144.

ARANHA, A. V. S.; PENA, C. S.; RIBEIRO, S. H. R.. Programa de inclusão na UFMG: o efeito do bônus e do Reuni nos quatro primeiros anos de vigência: um estudo sobre acesso e permanência. Revista em Educação, Belo Horizonte, v.28, n.4, p.317-245, 2012.

BARDIN, L.. Análise de conteúdo. Lisboa: Edições 70, 2011.

BEZERRA, T. O. C.; GURGEL, C. R. M.. A Política pública de cotas em universidades, enquanto instrumento de inclusão social. Revista Pensamento \& Realidade, v.27, n.2, 2012.

BONETI, L. W.. Exclusão e Inclusão Social: teoria e método. Contexto e Educação, v.21, n.75, p.187-206, 2006.

BRASIL. Decreto n.6096 de 24 de abril de 2007. Institui o Programa de Apoio a Planos de Reestruturação e Expansão das Universidades Federais - Reuni. Brasília: DOU, 2007.

BRASIL. Ministério da Educação. Plano de Desenvolvimento da Educação: Diretrizes Gerais do Programa de Reestruturação e Expansão das Universidades Federais: Reuni. Brasília: DOU, 2007.

BRESSER-PEREIRA, L. C.. A Reforma Gerencial do Estado de 1995. RAP, Rio de Janeiro, v.34, n.4, p.7-26, 2000.

BUCCI, M. P. D.. O conceito de política pública em direito. In: $\mathrm{BUCCl}, \mathrm{M}$. P. D.. Políticas públicas: reflexões sobre o conceito jurídico. São Paulo: Saraiva, 2006.
CAMARGO, B. V.; JUSTO, A. M.. Tutorial para uso do software de análise textual IRAMUTEQ. Florianópolis: UFSC, 2013.

CASTEL, R.. Metamorfoses da questão social. Petrópolis: Editora Vozes, 2010.

CASTEL, R.. A discriminação negativa: cidadãos ou autóctones?. Petrópolis: Vozes, 2008.

DIAS SOBRINHO, J.. Democratização, qualidade e crise da educação superior: faces da exclusão e limites da inclusão. Educação \& Sociedade, Campinas, v.31, n.113, p.1223-1245, 2010

DIAS SOBRINHO, J.. Educação Superior: bem público, equidade e democratização. Revista da avaliação da Educação Superior, Campinas, v.18, n.1, 2013.

DRUCKER, P. F.. Sociedade pós-capitalista. 7 ed. Rio de Janeiro: Campus, 1999.

FALEIROS, V. P.. Inclusão Social e Cidadania. INTERNATIONAL CONFERENCE ON SOCIAL WELFARE, 32. Anais. Brasília: 2006.

GIRON, G. R.. Políticas públicas, educação e neoliberalismo: o que tem a ver com cidadania?. Revista de Educação PUCCampinas, Campinas, n.24, p.17-26, 2008.

KUENZER, A. Z.. Da dualidade assumida à dualidade negada: o discurso da flexibilização justifica a inclusão excludente. Educação \& Sociedade, Campinas, v.28, n.100, p.1153-1178, 2007.

KUENZER, A. Z.. Exclusão includente e inclusão excludente: a nova forma da dualidade estrutural que objetiva as novas relações entre educação e trabalho. In: LOMBARDI, J. C.; SAVIANI, D.; SANFELICE, J. L.. Capitalismo, trabalho e educação. 3 ed. Campinas: Histedbr, 2005. p.77-95.

PASTORE, J.; SILVA, N. V.. Mobilidade social no Brasil. São Paulo: Makron, 2000.

PAUGAM, S.. L'éxclusion: l'etat dês savoirs. Paris: Seuil, 1996.

PEIXOTO, M. C. L.; BRAGA, M. M.. Ações afirmativas no ensino superior e as políticas de bônus para ingresso nos 
cursos de graduação uma Universidade Federal de Minas Gerais. Revista Brasileira de Estudos Pedagógicos, Brasília, v.93, n.233, p.166-188, 2012.

POCHMANN, M.; BARBOSA, A.; SILVA, R.; PEREIRA, M. A.; PONTE, V.. Atlas de Exclusão Social: Agenda não Liberal da Inclusão Social. São Paulo: Cortez, 2005.

PRESTES, E. M. T.; JEZINE, E.; SCOCUGLIA, A. C..

Democratização do Ensino Superior Brasileiro: O caso da Universidade Federal da Paraíba. Revista Lusófona de Educação, v.21, n.21, p.199-218, 2012.

RUA, M. G.. Políticas Públicas. 2 ed. Florianópolis: UFSC, 2012.

SALISBURY, R. H.. The Analysis of Public Policy: A Search for Theories and Roles. In: THEODOULOU, S. Z.; CAHN, M. A.. Public Policy: The Essential Readings. New Jersey: Prentice Hall, 1995. p.34-37.

SECCHI, L.. Políticas públicas: conceitos, esquemas de análise, casos práticos. São Paulo: Cengage Learning, 2010.
SILVA JÚNIOR, J.; SGUISSARDI, V.. Universidade Pública Brasileira no Século XXI: educação superior orientada para o mercado e intensificação do trabalho docente. Espacio Blanco, v.23, n.1, p.119-156, 2013.

SOUZA, C.. Políticas públicas: uma revisão da literatura. Sociologias, n.16, p.20-45, 2006. DOI: http://doi.org/10.1590/S1517-45222006000200003

VARGAS, H. M.; PAULA, M.. A inclusão do estudantetrabalhador e do trabalhador-estudante na educação superior: desafio público a ser enfrentado. Avaliação, Campinas, v.18, n.2, p.459-485, 2013.

VEIGA-NETO, A.; LOPES, M. C.. Inclusão e Governabilidade. Educação \& Sociedade, Campinas, v.28, n.100, p.947-963, 2007.

VEIGA-NETO, A.; LOPES, M. C.. Inclusão, Exclusão, In/Exclusão. Verve, Campinas, n.20, p.121-135, 2011.

WANDERLEY, M. B.. Refletindo sobre a noção de exclusão. In: SAWAIA, B.. As artimanhas da exclusão: análise psicossocial e ética da desigualdade social. Petrópolis: Vozes, 2001. p.19-23. 